\title{
THE LIGHTS USED TO BE BRIGHTER THERE: MARKET-DRIVEN STRATEGIES FOR REHABILITATING THE RETAIL TRADING AREAS OF MID-SIZED CITIES
}

\author{
Mohammed Y.A. Rawwas \\ University of Northern Iowa \\ Cedar Falls, IA \\ David Strutton \\ University of Southwestern Louisiana \\ Lafayette, LA
}

\begin{abstract}
The wellbeing of downtowns is an important issue. Yet key decision makers throughout the U.S. may have reached the point where they are ready to bid farewell to these historical focal points of commerce, entertainment, and political activity. Such an outcome would be quite unfortunate: in fact, some suggest the decline of city cores is one of the most pressing issues facing America today. In this study, a theoretical framework is developed incorporating supply- and demand-related factors that are likely to influence consumers' decision to shop or not shop downtown. The framework is then tested, using a consumer sample taken from three midsized American cities. Actionable recommendations regarding how downtown retail trading areas of midsized U.S. cities may be renewed are then developed and discussed.
\end{abstract}

\section{Introduction}

Petulia Clark's 1960's-era musical tribute to "downtown" rings increasingly hollow in the 1990s. These days, many smaller and midsized downtowns (hereafter, the term "downtown" is used without a size modifier) are just that: down. Actually, most have been for some time. For several decades running, most Americans apparently have accepted the steady decline of urban retailing centers as a necessary consequence of commercial, societal, and individual progress (Swan, 1995).

Many key decision makers may have reached the point where they are ready to bid farewell to these historical focal points of commerce, entertainment, and political activity (Frieden and Sagalyn, 1989). The days of small-town independent proprietors operating successful main street shops have generally yielded to sprawling suburban malls and massive retailers like Wal-Mart, K-mart, and Target. Are such changes just another price that must be paid in return for social or commercial progress? Possibly, but the costs associated with deteriorating downtown retailing bases are greater than many realize. In fact, the types of commer- 
cial and social problems widely assumed to be uniquely associated with the inner cores of cities may soon twist around and afflict people living in surrounding suburban areas (Porter, 1995; Schiller, 1994). The decline of inner city cores is perhaps the most pressing social issue facing America (Stone, 1995), although, admittedly, the decline of downtown retailing centers is but one of many social concerns in urban landscapes.

For a number of reasons, the welfare of downtown retail trading centers remains an important issue. But three factors dominate the rest. They are: downtowns (1) offer the most prominent reflection of healthy or unhealthy cities, (2) exist as the historical nucleus and cultural repositories of most communities, and (3) are (still) key employment centers (Leinenkugel, 1995).

At this point in the decline of America's urban infrastructure, Donne's classic assertion that "No man is an island ... every man is a part of the main" should strikes business strategists as uncommonly prescient. Donne's metaphor neatly captures the current relationship between traditional retailing centers in many midsized cities and the outlying business sectors that jointly form modern commercial systems. No commercial islands exist in today's global economy where one sector's wellbeing remains unaffected by the performance of other areas. When even the quality of the air we breathe is affected by decisions made hundreds of miles away, there is no room for isolationism in American business.

\section{Research Objectives}

Strategies for revitalizing the central retailing destinations that once encompassed the hearts of communities are receiving growing attention. So much so, in fact, that at this point discussions concerned with urban renewal are hardly news. Twenty years ago, planners who attempted to restore downtown retail sectors to their former glories were pioneers. By and large, such trailblazers slogged their way through the process the best they could. But now, given the hindsight developed from a two-decade history of revitalization efforts, it is obvious that Field of Dreams-type tactics - "if you built it, they will come" (Palma, 1992) — usually will not work. These failings apparently result in part from the fact that business strategies aimed at urban revitalization have rarely approached the issue from consumers' perspectives.

Market-based analyses therefore appears to represent a necessary first step to developing successful downtown revitalization strategies. Knowledge gained from such analyses could subsequently be used to improve private retail sectors' business decisions and public sectors' governance decisions. If it is driven by strategic concerns, this knowledge should reflect information concerned with how best to market downtowns, which business hours to keep, what types of stores to emphasize in downtown retailing mixes, or which types of streetscape improvements to make. Market-driven approaches to developing downtown revitalization strategies should also inform business and municipal developers regarding who cur- 
rent downtown shoppers are, who potential shopping candidates are, and what each group wants. Mindful of these imperatives, our first objective was to:

Develop a conceptually-based strategic model incorporating factors that influence consumer's decision to shop (not shop) downtown.

Then, following from the model, our second objective was to:

Profile differences in consumers who shop (do not shop) in the downtowns of small to midsized cities

and

Investigate whether differences existed between what shoppers and nonshoppers sought with respect to their downtown shopping experiences.

\section{Literature Review and Hypothesis Development}

The downtowns of most U.S. cities face a dilemma. They are widely viewed as being representative of their overall city identity, so cities of all sizes and in all regions are committed to successful downtown redevelopment. But beginning during the 1960s, and generally continuing since, the inner cores of midsized cities have generally lost population and income. During the same period, increasing traffic congestion (consisting largely of commuting workers) and the growing absence of other evening and weekend shoppers contributed to the relative unattractiveness of downtowns as shopping destinations. Retailers themselves grew increasingly averse to downtown locations because higher security was necessary, shoplifting was more common, and room for expansion was generally lacking. To stay abreast of their customers' changing preferences, retailers shifted their business focus from downtown areas to suburban locations. Downtown areas today usually feature proportionately less retail activity than their populations would otherwise suggest (Ettorre, 1995; Newman, 1995).

Still, in some urban settings, downtowns continued to provide viable retailing sites. Perhaps the important element sustaining the relative health of some downtowns lies in the fact that people still must enter them to work. Here and there, cities have also provided substantial financial incentives to retailers who choose to locate or remain downtown. Over the last two decades many urban areas have also experimented with a process known as gentrification. Gentrification occurs when older buildings are restored as new offices, homes, or retail sites. But efforts at downtown gentrification have not always been successful. Underground Atlanta, refurbished in the city's historical center in the 1980s, 
is widely viewed as a failure. Persuading consumers to drive downtown to acquire merchandise that is available elsewhere is clearly a challenging task.

In the development of retail strategy - as is true of most aspects of business strategy - one of the few real constants is change. Time marches on and, as any child who has ever set up a lemonade stand on a dead end street already knows, the marketplace is heartless. In recent years retailing powercenters - clusters of big stores like Wal-Mart, Home Depot, or Target - have incessantly hammered away at the high suburban market shares that malls had enjoyed for years (Khermouch, 1995). Malls, of course, grabbed most of their original shares from downtown shopping areas. The reason for both market shifts is simple: retailing outlets, as well as the locales housing those outlets, must change to satisfy shopper needs. Most shoppers today do not have time to browse around the far-flung assortment of retail outlets found in malls. More women work outside the home than ever before. Men, of course, continue to work, and spend record amounts of time on the job. Shoppers are thus likely to assign an increasingly high value to the convenience made possible by any site offering large selection (one-stop shopping), nearby parking, and late hours all in one place.

Nevertheless, if market forces really were the only influences that counted, downtown retailing centers would have virtually disappeared some years back. For instance, among many Americans the current nostalgia for old or familiar places is so strong that some downtowns have been able to successfully foster the illusion of activity where little would have occurred on its own (Tarricone, 1994). Other consumers simply are not willing to easily let go of their past, and downtowns are unquestionably a big part of America's past. Other downtowns have successfully renovated old theaters, enticed entrepreneurs to move in or current downtown workers to shop there by offering financial incentives, and, at times, coerced secondary financial support from federal or state level governmental sources. Of course, few downtowns will survive, much less prosper, merely on basis of the warm sentiments certain consumers may hold toward the romance of downtowns' better days-gone-bye or the occasional worker who scurries off during lunch to buy a sweater. That is where the need arises for a market-driven examination of the strategic forces that affect downtowns' futures.

These market-driven ebbs and flows in the identity of "desirable" retailing locations imply that the ability of downtown retail trading areas to entice a respectable proportion of shoppers back to their locales depends on their attractiveness relative to other trading area options. The notion of any retail trading center's relative attractiveness ought logically to be based on a combination of retailing, nonretailing, and aesthetic factors that are associated with it. Logically, specific differences in the attractiveness of an area to downtown shoppers and downtown nonshoppers then may be assessed as a means of gaining actionable insights regarding how to increase the attractiveness of downtown trading areas.

From a conceptual perspective, few restrictions exist on the number of factors that might be considered in a model evaluating the attractiveness of down- 
towns as shopping locations (Nevin and Houston, 1980). But, based on the existing literature, these factors should probably reflect issues broadly relating to retailing factors, environmental factors, and aesthetic characteristics associated with downtown locations (Chain Store Edge Executive, 1992; Robertson, 1995; Wilson, 1994). Retail factors should include issues such as the number and type of stores available downtown (Brown, 1994). Environmental (or nonretail) factors would need to address downtown issues that existed external to stores themselves (Taubman, 1987). Aesthetic characteristics could entail issues pertaining to considerations of convenience or culture (Rybczynksi, 1995).

All these factors or considerations represent supply-side issues. Moreover, each such factor may be associated to a greater or lesser degree with any downtown locale. Finally, strategically-driven action plans could be developed with respect to each if the proper information and insights were developed.

The influence of demographic or demand-side factors should also be considered in a model predicting how to renew downtowns as a retailing center. Demographic considerations should address issues like consumers' place of residence and work, gender, age, marital status, education and income, given that each factor clearly may influence their propensity to shop in downtown retail trading centers (Lorch and Smith, 1993). As a result, these demand-side factors are also evaluated in the model of the factors that may influence consumers to visit downtown. This set of supply-and demand-side factors that coalesce to contribute to the relative attractiveness or unattractiveness of a downtown trading area are summarized in Figure 1.

Creating a desirable image for a downtown shopping area will surely prove crucial to its strategic renewal efforts. Once this image is properly communicated consumers residing or working in outlying areas presumably can be moved through a hierarchy of effects; passing through stages that reflect "liking," "intention to visit," and, eventually, action downtown "shopping behaviors". The creation of a favorable retailing supply image thus appears to be a prerequisite to getting consumers to change their existing downtown shopping intentions and behaviors.

It follows that a broad variety of attributes should contribute to a downtown trading area's image. Issues like the breadth and depth of product/service assortment available, aesthetic considerations, convenience, and broad aspects of environmental ambience should each affect consumer's trading area choices (Bearden, 1977; Brown, 1989; Weisbrod, Parcells and Kern, 1984). Other issues such as crime or panhandling unquestionably also affect the attractiveness of downtown shopping areas, but were excluded from consideration in this study because they lie beyond the control of retail or urban planners. By contrast, the factors described in the above framework are each actionable. This characteristic should thus allow retailers, merchant associations, or municipal governments to develop strategies aimed at targeting consumers in ways that will renew the welfare of their downtown trading areas. 
Figure 1

Theoretical Model of Factors That Influence Consumers to Visit Downtown

\section{Supply-Side Factors}

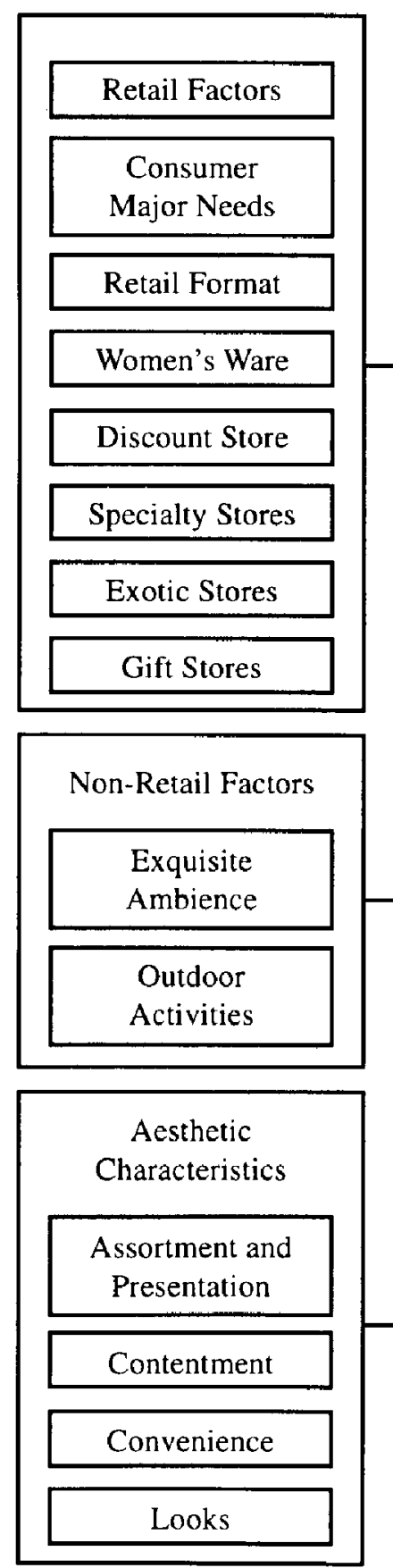

\section{Demand-Side Factors}

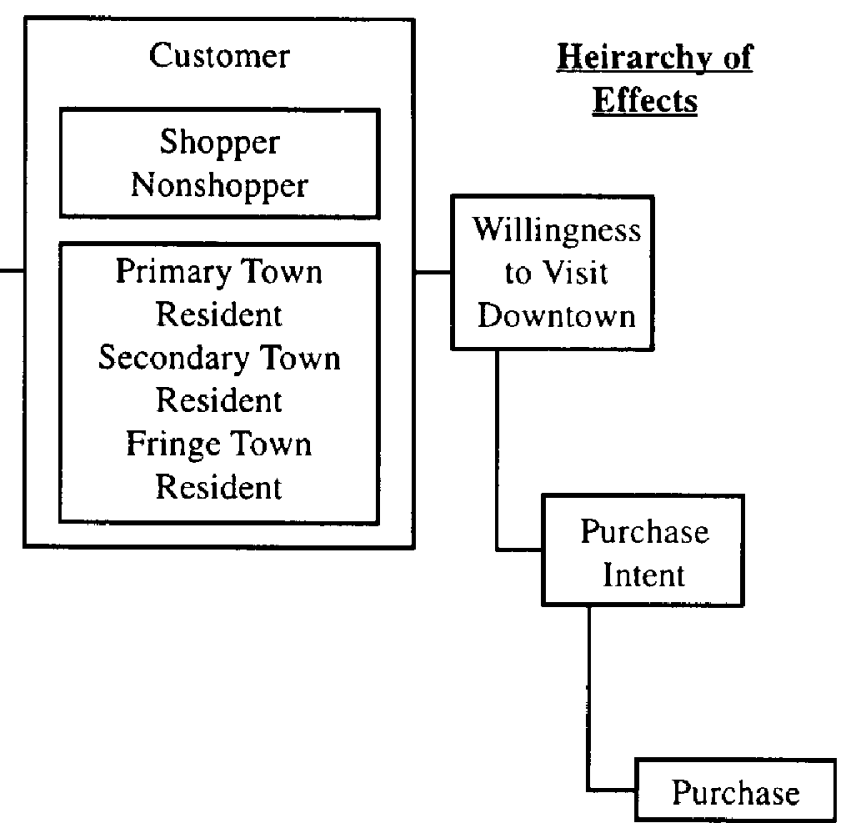


Consistent with this model and theory, the following hypotheses were tested:

Hypothesis 1: Downtown shoppers and nonshoppers will be characterized by significantly differing demographic properties.

Hypothesis 2: Downtown shoppers and nonshoppers will differ significantly regarding their perceptions of the importance of retailing and environmental factors typically associated with downtown trading areas.

Hypothesis 3: Downtown shoppers and nonshoppers will differ significantly regarding their perceptions of the quality of aesthetic factors typically associated with downtown trading areas.

\section{Method}

\section{Sample Development}

Data were obtained by mailing surveys to three randomly selected groups of 333 consumers. Members of each consumer group resided in one of three midwestern locales. The decision to investigate midsized downtown markets in this study was based on three strategic issues. These factors are discussed below:

First, larger central business districts that have successfully revitalized themselves in recent years typically have grounded their progress in gentrification processes. These gentrification efforts generally have been made possible through the combined efforts of regional corporate communities and the local municipal government. For instance, the recent rejuvenation of downtown Cleveland is almost entirely due to the combined efforts of its local government and private business sectors. Unfortunately, midsized cities usually lack the absolute corporate scale necessary to underwrite the huge makeovers required for successful gentrification (Heikkila and Kantiotu, 1992). Almost without fail, midsized cities must rely more on traditional marketing-oriented approaches to power their urban renewal efforts (Barrett and Greene, 1993).

Second, a large proportion of every dollar spent in a WalMart or Target store represents monies not spent in privatelyowned local stores. Many such stores traditionally have been located downtown. That several of Sam Walton's heirs are 
among the richest Americans provides glowing testament to their father's ingenuity and insight. But their wealth also illustrates that some $\$ 30$ billion fewer dollars are now circulating annually through America's smaller business communities (Rogers, 1995). Insights need to be developed regarding how downtown retailers operating in midsized cities might better overcome their scale limitations and these external threats to their continued existence.

Third, midsized downtowns typically do not face the overwhelming levels of crime against persons and property that are endemic to many downtown retailing environments in large cities. Strip shopping centers located downtown in larger cities spend up to $\$ 2$ more per square foot than comparable suburban shopping centers (Porter, 1995). These extra costs largely result from a need for more security, increased lighting, and continuous cleaning. More significantly, the prospect of crime against employees and customers creates an unwillingness to work in and patronize such retail centers, and restricts operating hours. Because these factors are beyond the purview of a study such as this, a decision to study smaller markets is reinforced.

The first sampling domain was a midwestern city having approximately 40,000 inhabitants (designated as the "primary" domain). The second domain was a nearby city having approximately 110,000 residents (designated as the "secondary" domain). The third population sampled consisted of consumers residing outside the corporate boundaries of either municipality (designated as the "fringe" domain). Respondents taken from within each sampling domain were grouped together during all subsequent analysis, a process which should increase the generalizability of the results. Each municipal location featured a distinct downtown shopping district.

Of the 999 instruments mailed, 225 were returned for a response rate of $22.5 \%$. Of this total, 218 instruments were deemed usable for analysis. This response rate compares favorably with returns realized by other retail studies sampling the general populace (Dabholkar, Thrope and Rentz, 1996; Rooks and Weinroth, 1993; Welch and Massey, 1987).

The demographic data revealed that most respondents were over 35 years of age and married. Respondents also generally had at least some college education and higher than average annual incomes for this U.S. region (Statistical Abstracts 1995). Other information relating to the demographic distributions observed is provided in Table 1.

\section{Measurement}

Retail shopping area image represents a composite of issues that consumers perceive as characteristic of the trading locale. A number of questions should be 
Table 1

Demographics

1. Age

Under 18

$18-24$

$25-34$

$35-49$

$50-64$

65 and over

2. Gender

$$
\text { Male }
$$

Female

3. Marital Status

Married

Not Married

4. Total Household

Yearly Income $(1,000 s)$

Under $\$ 10$

$\$ 10-\$ 19$

$\$ 20-\$ 29$

$\$ 30-\$ 39$

$\$ 40-\$ 49$

$\$ 50-\$ 59$

$\$ 60$ - $\$ 69$

$\$ 70$ or over

\section{Highest Level of Education}

$\begin{array}{lr}\text { High School or less } & 23.5 \% \\ \text { Some University } & 39.0 \\ \text { University Degree } & 29.6 \\ \text { Graduate Degree } & 8.0\end{array}$

6. Town of Residence

$$
\text { Primary }
$$

Secondary

Fringe

$38.0 \%$

62.0

$58.2 \%$

41.8

$13.9 \%$

10.7

19.5

19.6

9.9

13.2

7.3

4.9
7. Town of Work

Primary

Secondary

Fringe

8. Primary Downtown As a Shopping Destination

Yes

No

9. Advertising Media That

Attracts Attention the

Most to Primary Downtown

Direct Mail

T.V.

$9.0 \%$

Radio

23.4

Newspaper

Billboards

34.9

27.5

$58.4 \%$

41.6
10. The Time Subjects

Usually Go Downtown

Weekdays:

During morning

At lunch

$5.9 \%$

During afternoon

5.9

29.2

During evening

8.6

Saturdays

47.0

Sundays

3.2

11. Mark-downs As a Motivating Factor to Shop Downtown Yes

No

$64.4 \%$

12. The Appealing Word in Visualizing Downtown

Parkade

Mainstreet

35.6

$58.0 \%$

42.0 
used to capture each shopping area image dimension, especially in exploratory studies where no guiding framework is present. For this reason, the instrument was divided into four sections. The first section featured questions addressing the importance to consumers of the availability of various retail store types (e.g., drugstores, office supply stores, factory outlets) that may attract shoppers downtown. The second section addressed the importance to respondents of environmental issucs like cultural activities, historical ambiance, or parking, which may stimulate downtown traffic when consumers are considering where or whether to shop. In each of these two sections, consumer beliefs were assessed using five-point Likert-type scales, with (1) indicating "Extremely Unimportant" and (5) indicating "Extremely Important." The third section dealt with consumer perceptions of the quality of various aesthetic factors that may be associated with a downtown's retailing environment. Again, consumer responses were measured along a fivepoint scale, but now (1) indicated "Miserable" and (5) indicated "Excellent." The instrument's final section measured demand-side related demographic characteristics of respondents and featured "yes-no" questions that permitted respondents to be classified into downtown shopper-nonshopper categories.

To summarize the patterns of correlations existing among the questions, an exploratory factor analyses with varimax rotation was performed on 35 items measuring the importance of retail store-types. This analysis identified storetype subgroups viewed by this sample as similarly important in their ability to attract customers downtown. The roots criterion and scree test criteria were used in combination to determine the suitable number of factors to extract. That juncture on the Scree plot with a large break in the plot of the Eigen roots was assumed to be the point where factor extraction should stop with the additional provision that all eigenvalues be near or greater than one.

This procedure revealed that 27 items loaded on seven retail store-type factors. Eight items were dropped because of low loadings. Based on the identity of the items loading on them, these factors were labeled as focused consumer needs stores, traditional retail format stores, women's wares stores, discount stores, specialty stores, discount stores, exotic stores, and gift stores, respectively. An identical scale building procedure was used with respect to the items measuring downtown environmental issues. Two factors, labeled old fashioned values and activities and circumstances external to stores, were extracted. The first construct reflected circumstances relating to historical buildings, period images, artistic factors, and/or cultural activities that may be present downtowns. The latter factor encompassed considerations relating to the availability downtown of free parking, special events, parks and picnic areas, and recreational activities.

Four factors were extracted from the final factor analysis, which was performed on fifteen items measuring perceptions of downtown trading area's aesthetic characteristics. The emergent factors were labeled as assortment and atmospheric presentation, appearance, quality transactions, and convenience, respectively. Characteristics such as a downtown trading area's merchandise vari- 
ety, window displays, layout, building facades, and quality of goods/services loaded on the assortment and atmospheric presentation factor. Appearance reflected the cleanliness and attractiveness of a downtown trading area. A downtown's traffic flow patterns (e.g., straight vs. serpentine), parking accessibility, accessibility to disabled persons, and shopping hour convenience correlated highly, thus fashioning the convenience construct. Finally, salesperson friendliness, safety, and general costs of a downtown's goods and services loaded together to form a quality transactions factor. Table 2 summarizes the items, loadings, and coefficient alphas corresponding to each factor.

\section{Analysis}

The hypotheses were tested using MANOVA. The MANOVA procedure used to test the second and third hypotheses also employed a covariate analysis, controlling for respondents' town of residence and of work. Covariate analysis increases the power of a MANOVA significance test to detect true differences in downtown shopper/nonshopper perceptions. Removing the possible effects of residence and employment on respondents' perceptions of their downtown trading areas was desirable because those conditions might have biased the results. On the other hand, no strategic need existed to address these effects since neither retailers nor municipal planners can meaningfully influence any targeted consumer group's places of residence or employment.

Discriminant analysis was also used. Using discriminant analysis in conjunction with MANOVA facilitates insights into the direction and intensity of any significant relationships. While MANOVA tests for significant differences from the null hypothesis of no differences in the demographic characteristics (or perceptions of what is important in a downtown shopping experience) of downtown shoppers/nonshoppers, discriminant analysis determines the weights of the combination of criterion variables that optimize departure from the null. Examining each demographic or perceptual variable's contribution to the discriminant function facilitates a more precise interpretation of any differences in demographics or image perceptions across downtown shoppers and nonshoppers.

\section{Results}

\section{Objective 1}

MANOVA was used to test the hypothesis concerned with whether consumers who shop or did not shop "downtown" would display significantly different demographic characteristics. Demand characteristics included in the model were income, marital status, place of work, place of residence, age, gender, and education. MANOVA revealed a significant overall difference in the demographic characteristics associated with downtown shoppers and nonshoppers. Using discriminant analysis to determine the direction and intensity of the hypothesized relationships across the shopper categories was thus appropriate. 
Table 2

\section{Retail Businesses That May Attract Customers To Primary Downtown (Factor Analysis)}

\begin{tabular}{lll}
\hline Item & Factor Loadings & Coefficient Alpha \\
\hline
\end{tabular}

1. Retail Factors

Consumer Needs Stores

Financial services (e.g., stock brokers, banks) $\quad .711$

Personal services (e.g., barbers, hair

dressers, ins., medical, travel ins.) $\quad .688$

Office supplies $\quad .676$

Photo studios $\quad .602$

Computers, electronics $\quad .578$

Hardware $\quad .511$

Furniture $\quad .503$

Shoes - men's, women's and children's $\quad .486$

Traditional Retail Format Stores $\quad .77$

Box (Limited-line) store (e.g., Aldi) $\quad .738$

Supermarket (e.g., Hy Vee) $\quad .707$

Drugstores $\quad .675$

Department store $\quad .550$

Fast-Food Restaurants (e.g., McDonald's) $\quad .534$

Video Sales and Rentals $\quad .454$

Women's Wares Stores $\quad .84$

Women's Wear $\quad .776$

Women's Accessories $\quad .708$

Discount Stores $\quad .84$

Off-Price Store (e.g., T.J Maxx) $\quad .853$

Factory Outlet (e.g., Galt Sand, Liz Claiborne) .848

Large Specialty Store (e.g., The Limited) $\quad .727$

Specialty Stores $\quad .80$

Specialty food (e.g., coffees,

French pastries, candies) $\quad .786$

Specialty gifts (e.g., boutiques, lingerie) $\quad .709$

Exotic Stores

.66

Hobby stores $\quad .720$

Sports apparel $\quad .577$

Luggage, executive gifts $\quad .505$

Jewelers $\quad .479$

Gift Stores
Cards and gifts

Children's clothes and gifts $\quad .634$ 
Table 2

\section{Retail Businesses That May Attract Customers To Primary Downtown (continued)}

\begin{tabular}{lll}
\hline Item & Factor Loadings & Coefficient Alpha \\
\hline
\end{tabular}

2. Non-Retail Factors

Old-Fashioned Values

Preservation of historic buildings

.828

A downtown that projects image

(e.g., ethnic or time period)

Artistic environment (e.g., art studios, art galleries)

Cultural activities (e.g., live theater, musical performances)

Activities and Circumstances External to Stores

Free Parking

Special events and festivals

.688

Availability of parks and picnicking areas

Recreational activities (e.g., biking, water activities, movies)

\section{Aesthetic Characteristics}

Assortment and Atmospheric Presentation

Variety of stores

Window and in-store displays

Variety of goods/service

Store layout

Building facade

Quality of goods/service

Quality Transactions

Friendliness of salespeople $\quad .794$

Safety $\quad .743$

Cost of goods/service $\quad .633$

Convenience

Traffic flow (straight vs. serpentine

$$
\text { Main Street) }
$$

Parking convenience

Store accessibility to handicapped patrons $\quad .634$

Shopping hours

Appearance 
This analysis revealed that only one demographic variable, income, significantly discriminated between downtown shoppers and nonshoppers. Consumers reporting higher incomes were significantly more likely to shop downtown. Surprisingly, no other demand-related factor (e.g., marital status, place of work or residence, age, gender, and education) was significantly related to this sample's downtown shopping behaviors. One must conclude that the first hypothesis was not supported. Mean values, canonical loadings, and multivariate and univariate significance tests associated with this analysis are reported in Table 3.

Table 3

Analysis of Demographic Differences

\begin{tabular}{lcccc}
\hline & & & \multicolumn{2}{c}{ Means } \\
\cline { 5 - 5 } Variable & Canonical Loading & F-test & Shoppers & Nonshoppers \\
\hline Income & .6451 & .022 & 4.214 & 3.235 \\
Status (dummy) & .2605 & .437 & 0.643 & 0.568 \\
Work1 (dummy) & .2360 & .398 & 0.393 & 0.314 \\
Live2 (dummy) & .1782 & .986 & 0.140 & 0.216 \\
Age & .1273 & .393 & 3.607 & 3.372 \\
Work2 (dummy) & .0997 & .721 & 0.446 & 0.412 \\
Sex (dummy) & .0512 & .583 & 0.321 & 0.373 \\
Education & .0362 & .897 & 2.232 & 2.255 \\
Live1 (dummy) & .0052 & .750 & 0.482 & 0.451 \\
\hline
\end{tabular}

Multivariate

Chi-Square

Chi-Square significance

Percent of variance explained

$100 \%$

Percent Correctly Classified

Analysis Sample

$66.36 \%$

Hold Out Sample

$54.81 \%$

\section{Objective 2}

The broad content of the propositions associated with the second research objective was illustrated in Figure 1. MANCOVA was used to test the second hypothesis that downtown shoppers and nonshoppers would exhibit significantly differing perceptions regarding what they view as important in a downtown shopping experience. After adjusting for the possible influence of work and residence, significant overall differences were revealed in the perceptions held by shoppers and nonshoppers. Discriminant analysis again was used to determine 
the direction and intensity of the univariate relationships across the downtown shopping/nonshopping groups.

Downtown shoppers were significantly more likely than nonshoppers to view the downtown presence of specialty stores as important. But nonshoppers were more likely to report that they felt the downtown presence of discount and traditional retail format stores was important. This implies the availability of these store types should increase the likelihood that downtown nonshoppers would alter their shopping behaviors. While downtown shoppers apparently seek more depth in product lines (availability), nonshoppers appear more interested in value and the width of product mix available. These latter properties are presumably more widely available in suburban retail settings.

When evaluated against some rehabilitative efforts that have recently unfolded in a few midsized downtowns the strategic implications of these results are particularly evident. Some cities have begun to revive their long-dormant downtown trading areas by offering deeper product lines. Burlington, Iowa, and Stillwater, Minnesota are each success stories in progress. Each city has largely built its renewal around decisions to feature deep product lines of a single specialty product, antiques (Business Directory, 1995). One will recall from the demographic analysis that downtown shoppers generally enjoy higher incomes than nonshoppers. Because shoppers are apparently more interested in the sorts of unique items that theoretically could be more widely available downtown as opposed to malls or shopping centers, these results imply that downtown nonshoppers can be expected to seek more value and assortment in downtown offerings.

When compared with nonshoppers, downtown shoppers also felt that "oldfashioned values" were more important. Since these downtown shoppers tended to have higher incomes it may be inferred that they are a bit more sophisticated or cultured than their nonshopping counterparts. Consumers who shopped downtown may have elected to patronize the locale because they were more appreciative of the historic buildings, art, cultural activities, and generally erudite image that they perceived to be available there.

Downtown shoppers also assigned more favorable evaluations to various aspects of the downtown's aesthetic characteristics, (i.e., hypothesis 3). Differences existed between the groups with respect to two factors: "quality transactions" and "assortment and atmospheric presentation." Each factor captures a broad range of characteristics that may attract shoppers downtown. For instance, while each shopping group assigned above average ratings to the aesthetic factors, nonshoppers evaluated the friendliness of downtown sales staffs, safety, and considerations of cost less favorably than shoppers. Downtown nonshoppers were also less favorably impressed with the variety of stores, window and point-of-purchase (POP) displays, variety of goods/services, store layouts, and quality of goods/services available downtown. To attract more nonshoppers downtown, retailers apparently should take action aimed at addressing these particular shortfalls. 
Because discriminant analysis generates a linear function based on the criterion variables best distinguishing shoppers from nonshoppers, the importance of each criterion in discriminating the groups is given by the relative size of the canonical loadings. In descending order, the downtown characteristics exerting the greatest influence on overall group differences were: "Quality Transactions," "Old-Fashioned Values," "Assortment \& Amospheric Presentation," "Discount Stores," "Specialty Stores," and "Traditional Retail Format Stores." Two of the first three factors are associated with a downtown's aesthetic characteristics.

The overall size of the mean values associated with the retail and nonretail factors indicated that, regardless of their shopping behaviors, this sample believed most of the shopping area characteristics investigated were at least somewhat important. Regardless of their shopping behaviors, those persons sampled also generally felt that the aesthetic characteristics of their downtown was at least fair. Convenience was the sole exception to this trend. Nonshoppers felt the level of "convenience" associated with a downtown shopping experience was relatively poor. Again, the strategic implication is that downtown retailers should increase the convenience or perception of the convenience associated with a downtown shopping experience. Such an action should entice more nonshoppers to venture downtown.

Given the absence of significant differences across the shopper groups with respect to the following dimensions, one may likewise conclude that non-retail factors such as "activities and circumstances external to Stores" and aesthetic characteristics such as "convenience" and "appearance" are equally important to both groups. "Appearance" was seen as particularly important by both shoppers and nonshoppers. The means, canonical loadings, and multivariate and univariate significance tests associated with this analysis are shown in Table 4.

\section{Strategic Implications}

For years, retail strategists and public planners have too frequently shared an attitude of "why try to develop in an area that is more difficult to develop." But now, the easy, early pickings for retailers and urban planners are mostly gone. Downtowns are usually situated in what should be economically viable locations, e.g., near a port, river, or transportation nexus. Population density is another telling characteristic of downtowns. Strategically speaking, downtowns simply have or are near too many people to be ignored. Consequently, downtown retail centers clearly offer an attractive option retailers who could benefit from close proximity to population, tourism or entertainment centers, central business districts, or locale near the center of the logistical infrastructure. In the near term private and public developers are increasingly likely to realize that they have an implied responsibility to their city, society and selves to attempt to renew their downtown's well being. But the fact remains that retail trading areas situated in downtown locations generally cannot compete on an equivalent footing with malls. Nor can they reasonably aspire to cultivate distribution structures that will allow 
Table 4

\section{Analysis Of Factors That May Attract Customers To Primary Downtown Controlling For Place Of Residence And Work}

\section{Retail Factors}

\begin{tabular}{lcccc} 
& & & \multicolumn{2}{c}{ Means* } \\
\cline { 5 - 5 } Variable & Canonical Loading & F-test & Shoppers & Nonshoppers \\
\hline Discount Stores & .333 & .019 & 3.46 & 3.75 \\
Specialty Stores & -.305 & .031 & 3.37 & 3.70 \\
Traditional Retail & & & & \\
$\quad$ Format Stores & -.297 & .036 & 3.80 & 3.59 \\
Women's Wares Stores & -.110 & .432 & 3.73 & 3.82 \\
Gift Stores & .097 & .489 & 4.00 & 3.92 \\
Consumer Needs Stores & .090 & .520 & 3.66 & 3.61 \\
Exotic Stores & .067 & .634 & 3.49 & 3.45
\end{tabular}

\section{Non-Retail Factors}

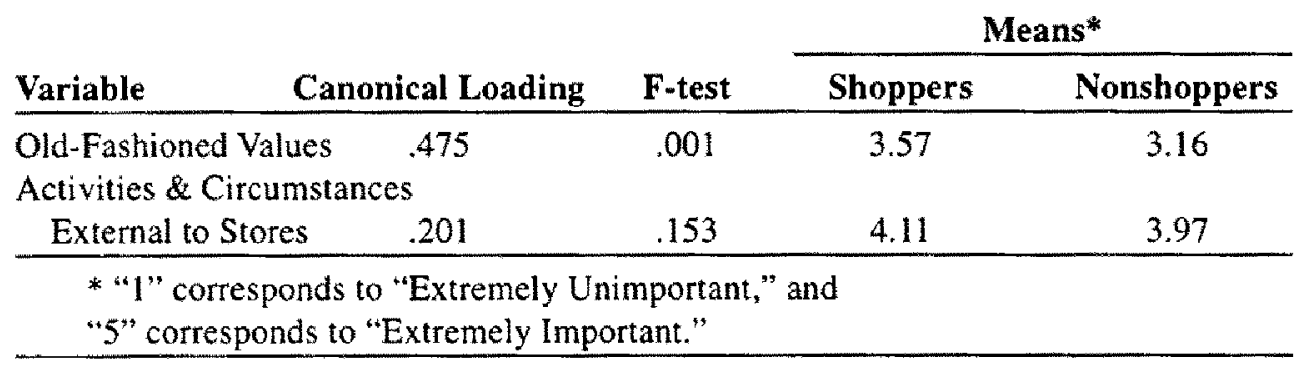

\section{Aesthetic Characteristics}

\begin{tabular}{|c|c|c|c|c|}
\hline \multirow[b]{2}{*}{ Variable } & \multirow[b]{2}{*}{ Canonical Loading } & \multirow[b]{2}{*}{ F-test } & \multicolumn{2}{|c|}{ Means* } \\
\hline & & & Shoppers & Nonshoppers \\
\hline Quality Transaction & .536 & .000 & 3.70 & 3.37 \\
\hline \multicolumn{5}{|c|}{ Assortment and Atmospheric } \\
\hline Presentation & .447 & .002 & 3.44 & 3.18 \\
\hline Convenience & .146 & .298 & 3.03 & 2.95 \\
\hline Appearance & -.089 & .525 & 3.67 & 3.72 \\
\hline \multicolumn{2}{|c|}{ Overall MANOVA } & \multicolumn{2}{|r|}{.000} & \\
\hline \multicolumn{2}{|l|}{ F-test value } & \multicolumn{2}{|r|}{3.661} & \\
\hline \multicolumn{2}{|c|}{$\begin{array}{l}\text { * "l" corresponds to "Miserable," and } \\
\text { "5" corresponds to "Excellent." }\end{array}$} & & & \\
\hline
\end{tabular}


them to offer pricing levels more competitive than those already available in nationally prominent discount stores.

This set of market characteristics provide a useful backdrop against which to interpret these results. Apparently, these results suggest that for waning downtown retailing districts to approach their former vigor, they must develop a series of strategically compelling competitive advantages that provide reasons why more people would want to begin shopping there again. The findings imply that vibrant retailing activity in downtown retail trading areas will be reborn only when such locations boast sustainable competitive advantages (i.e., old fashioned values such as the preservation of older buildings) and occupy defensible niches (i.e., specialty stores such as antique or handicraft shops) that cannot be easily replicated elsewhere. These results also suggest that downtown business communities should capitalize on their heritage - those aspects which make them unique. Such an approach would give downtowns a distinct positioning advantage over faceless malls and look-alike suburban stores.

The flow of this study's results (see Figure 1) implies that two sets of decision criteria are likely used in most of consumers' patronage decisions: (1) those attributes that affect a downtown districts overall shopping image, and (2) those that affect a consumer's preference for particular retail outlets. Thus, when individual retailers compete vigorously and do those things necessary to derive a desirable store image, they simultaneously bolster the image of their entire shopping area. Thus, a spirit of "one for all and all for one" truly should prevail relative to downtown revitalization efforts. But this findings also imply that individual retailers cannot reasonably hope to revive the flagging fortunes of downtowns on their own. On their own, individual retailers cannot reasonably hope to effect "old-fashioned values" throughout an entire downtown. Nor can they ensure that an ideal retailing mix is available throughout a downtown trading area. This is why an overarching strategic plan that incorporates the concurrent efforts of governmental and community activists should also be engaged. Such efforts would complement the classic competitive tactics of retailers aimed at delivering for themselves a more auspicious retailing mix or set of atmospherics.

The inner retailing cores of most midsized American cities have declined for many reasons. This urban decline thus represents a complicated problem. It is widely recognized that simple solutions to complex problems are rare. Moreover, it is understood that successful urban revitalization will require enormous resources. The nature of this problem and scope of these resources suggests the burden of renewal efforts should be borne proportionately across the broad range of publics who affect or are affected by a given downtown's relative welfare. These publics include retailers, nonretailing businesspeople, entrepreneurs, community activists, and public servants.

The cooperation and coordination of private and public sectors is undoubtedly crucial to the success of virtually all downtown renewal strategies. This implies that in the development of such strategies some overarching organiza- 
tional body should be established and assigned the responsibility of bridging the value gaps held by these disparate groups. This organization should also ensure that the efforts of the private and public sector are cohesively directed toward mutually acceptable outcomes. This could be achieved by forming private-public partnerships whose basic mission is to reinvent and reinvest in the downtown in question. Based on these data, it is apparent that a planning commission representing private sector retailers and public sector government offices would do well to devise a plan that operationalizes two broad tasks: the establishment of specialty stores and the rejuvenation of what were termed old-fashioned values.

This study further indicates that a coherent downtown redevelopment strategy must begin with a fundamental understanding of what the market in question seeks (or feels is absent) from their downtown shopping experiences. Working together, relevant constituencies operating within the trading area could then strive to deliver to the market the features it has singled out as desirable. Only downtown retailing attributes that are unique, or devised in such a way as to appear unique, within a relevant geographical market, will promote and support viable levels of business.

In this study, the significance of the "old-fashioned values" construct implies that downtowns may be able to carve out a position of relative strength by doing business the old-fashioned way. By positioning downtown shopping experiences as being more like they once were, retail and public policy strategies apparently may be to cultivate a more viable future for downtowns. This would, by turns, require strategic goals based on exploiting downtowns' historic appearances, and on generally promoting downtowns as traditional social, cultural, and entertainment centers. In this regard, businesspeople would also do well to stress the community and cultural pride that derives naturally from a healthy downtown. A sense-of-place and an appreciation for history are likely to prove important to the future "self-concepts" of cities, given that virtually all American cities started as port or rail towns featuring vital downtowns. Naturally, the "product offering" that is a downtown would have to be reformulated in ways consistent with these claims of old-fashioned values. Retailers are clearly incapable of doing this alone.

The results of this study also underscore the multidimensional nature of the opportunities currently enjoyed by downtown retailers. Business strategists acting on behalf of downtown interests apparently can increase the vitality of their districts as shopping destinations by purposefully operating on selected aspects of the retail factors, nonretail factors, and aesthetic characteristics evaluated in this study. For example, government officials could endeavor to provide the sorts of incentives necessary to stimulate the private sector's retail development or the maintenance of the right mix of stores. The city would be responsible for providing technical information, assistance, incentives, and loans to encourage the necessary sorts of private property investments and improvements. Innovative, nontraditional contributions to the development of the desired retailing mix could come in the form of helping to solve regulatory or zoning problems, the forma- 
tion of development organizations to support the project and in some cases functioning as owners or developers themselves. The public sector would also have to take actions that enhance public property, leading to improvements in the downtown's atmospheric presentation. These could include traditional activities such as streetscape or lighting improvements, and landscaping.

Community activists, on the other hand, certainly would have a critical role to play in the preservation of older buildings, the advancement or conservation of a compatible artistic environment, and the promotion of appropriate cultural activities. In this regard, community activists will always enjoy an advantage based in their intimate knowledge and understanding of what is unique in terms of the artistic dimensions of their downtowns. These insights can help them promote the right types of historical development.

Retail strategists, of course, are largely responsible for insuring that quality transactions between stores and consumers transpire, that a suitable assortment of goods and services is available, and that a suitable atmosphere is developed. Retailer associations might be used to initiate measures aimed at establishing specialty stores with a common theme. Such stores could feature unique products or services that complement one another. Retailers should also plan to improve product offerings, window displays, merchandising and marketing techniques.

Finally, the results associated with the model suggest that the success of downtown revitalization efforts may in large part depend on how effectively two economic standbys - supply and demand - are addressed. In this instance, however, the conventional relationship between these two elements ought to be reversed. Specifically, the results imply that to revitalize downtown trading areas demand for retailer services should be established before supply is furnished. Demand could be grown, for instance, by having Chambers of Commerce engage in strategic development aimed at attracting more and more high paying jobs downtown. This could be achieved by influencing state officials to offer incentives such as tax abatements to new businesses (including manufacturers).

Once consumer demand for retail services and products has been established in this manner, the supply of "appropriate" retailing services would likely expand as a natural consequence. At that point, the opportunity would emerge to fine tune the mix and number of specialty stores downtown, as would the opportunity to purposefully improve selected aspects of the public infrastructure of the downtown in question. Infrastructure encompasses parking, lighting, street sidewalks, public restrooms, trees, parks, and so forth.

With respect to these supply and demand issues, working agreements could be enjoined between all involved publics that permit each party to concentrate on what it does best, thus allowing other publics to exercise their own distinctive strengths. These "strategic partnerships" should include the mayor, top government officials, public agencies, downtown resident associations, retail associations, and non-retailing businesses. Various aspects of the downtown community 
life, heritage and ideals, as well as land use and retail design issues ought to be deliberated (Bramhall, 1992).

Working together in this fashion should allow natural synergies to develop. All the publics having a stake in a given downtown's welfare would do well to remember that they should hang together in these renewal efforts. Otherwise, borrowing from the words of Benjamin Franklin, they will surely hang separately ("hang" as in watching the slow, inevitable strangulation of something that should be dear to them). These publics would then be left with little more than a doughnut hole in place of what used to be the lively center of their cities.

\section{Limitations and Future Research}

These findings must be evaluated in light of certain limitations. Any discussion derived from a single, cross-sectional study reporting consumer responses is less than completely generalizable. This shortfall can be addressed in part by investigating these same issues using different samples taken from other regions of the country, or by developing longitudinal studies of these same effects. This study is also limited in that issues such as land-use, technology, entertainment, employment patterns, or crime that also may influence consumers' downtown shopping behaviors are not considered. The possible influence of such factors on downtown revitalization efforts should be investigated in future research.

\section{References}

Barrett, K. and R. Greene. "Return From the Crypt." Financial World 162, 5 (1993): 52 53.

Bearden, W.O. "Determinant Attributes of Store Patronage: Downtown Versus Outlying Shopping Centers." Journal of Retailing 53,2 (1997): 15-22.

Bramhall, B. "Building People Power in Three Cities." Planning 58 (November 1992): 23-26.

Brown, S. "Retail Location Theory: The Legacy of Harold Hotelling." Journal of Retailing $65,4(1989): 450-470$.

Industries Journal 14, 4 (1994): 542-576.

Dabholkar, P.A., D.I. Thrope and J.O. Rentz. "A Measure of Service Quality for Retail Stores: Scale and Validation." Journal of the Academy of Marketing Science 24, 1 (1996): 3-16. 
Ettorre, B. "Should Businesses Remain in the Inner Cities?" Management Review 84, 5 (1995): 13-18.

Frieden, B.J. and L.B. Safalyn. Downtown Inc.: How America Rebuilds Cities. Cambridge: MIT Press, 1989.

Heikkila, E.J. and C. Kantiotu. "Calculating Fiscal Inputs Where Spatial Efforts Are Present." Regional Science and Urban Economics 22, 3 (1992): 475-490.

Khermouch, G. "Target Hits Bullseye." Brandweek 36, 23 (1995): 22-26.

Leinenkugel, J. "Urban Revitalization: It's Not Just for Large Cities." Executive Speeches 9 (February/March, 1995): 12-16.

Lorch, B.J. and M.J. Smith. "Pedestrian Movement and the Downtown Enclosed Shopping Center." Journal of the American Planning Association 59, 1 (1993): 75-86.

Newman, O. "Defensible Space - A New Physical Planning Tool for Urban Revitalization." Journal of the American Planning Association 61, 2 (1995): 149-155.

Nevin, J.R. and M.J. Houston. "Image as a Component of Attraction to Intraurban Shopping Areas." Journal of Retailing 56, 1 (1980): 77-93.

Palma, D. "The Top Ten Ways to Revitalize Your Downtown." American City \& Country 23 (November, 1992): 48-55.

Porter, M.E. "The Competitive Advantage of the Inner City." Harvard Business Review (May/June, 1995): 55-71.

Robertson, K.A. "Downtown Redevelopment Strategies in the United States: An end-ofthe-Century Assessment." Journal of the American Planning Association 61, 4 (1995); 429-437.

Rooks, W.A. and J. Weinroth. "An Empirical Confirmation of Dual Strategies Used in Marketing High-Technology Goods and Services: The Decision-Supporting Software Example - Part One: Theoretical, Philosophical, and Pragmatic Foundations for the Research." Journal of Professional Services Marketing 9, 1 (1993): 173-181.

Rogers, D. "Surviving the Supercenter's Shadow." Supermarket Business 50, 1 (1995): $35-40$.

Rybczynksi, W. "Culture's Urban Fortunes." Civilization (November/December, 1995): 33-35.

Schiller, R. "Vitality and Visibility: Challenge to the Town Center." International Journal of Retail \& Distribution 22, 6 (1994): 46-50. 
Smallwood, C. "A Matter of Pride." American City \& Country 12 (February, 1994): 47 51 .

Stanwood, P.G. John Donne and the Theology of Language. Columbia, MO: University of Missouri Press, 1991.

Statistical Abstracts of the United States: The National Data Book. U.S. Department of Commerce. Washington, DC: 1995.

Stone, N. "Old Problems, New Solutions." Harvard Business Review (May/June, 1995): 18.

Swan, C. "Demography and the Demand for Housing - A Reinterpretation of the MankivWeil Demand Variable." Regional Science \& Urban Economics 25, 1 (1995): 41-58.

Tarricone, P. "A League of Their Own.” Civil Engineering 5 (1994): 58-61.

Taubman, A.A. "Challenging Myths That Plaque Retail Development." Retail Estate Finance Journal 25 (Summer, 1987): 61-64.

"The Downtowns Strike Back: Coexistence Now the Goal for City Retail." Chain Store Age Executive 68, 11 (1992): 64-66.

“The Ultimate Sales \& Credit Tool (1994-1995).” American Business Directories. Omaha, NE: University of Nebraska Press, 1996.

Weisbrod, G.E., R.J. Parcells and C. Kern. "A Disaggregate Model for Predicting Shopping Area Market Attraction." Journal of Retailing 60, 1 (1984): 65-83.

Welch, J.L. and T.K. Massey. "A Data Collection Alternative for Services Professionals: The 'Answer Check."' Journal of Professional Services Marketing 3, 2 (1987): 35-45.

Wilson, M. "Retail Goes Downtown: Building Stores in Urban Markets." Chain Store Age Executive 70, 9 (1994): 28-30.

Mohammed Y.A. Rawwas (Ph.D., University of Mississippi) is an Assistant Professor of Marketing at the University of Northern Iowa. His primary research interests lie in the areas of international marketing and ethics. Dr. Rawwas's research has appeared in the Journal of Business Ethics, Journal of Promotion Management, Marketing Education Review, Journal of International Consumer Marketing and the Journal of Business Research, among others.

David Strutton (Ph.D., University of Mississippi) is the Acadiana Bottling Professor of Marketing and J.W. Steen Professor of Business Administration at the University of Northern Iowa. His research has appeared in the Journal of Advertising Research, Journal 
of the Academy of Marketing Science, Journal of Macromarketing, Journal of Personal Selling \& Sales Management, and the Journal of Business Research, among others. Strutton is co-author of Marketing Channels: A Relationship Management Approach (Richard D. Irwin \& Co., 1996). 